aspects of care that can be optimised to reduce peri-procedure complication and mortality. Our 30-day mortality rate 3\% is well below compared to the national level. As a result, we recommend use of traffic light system with unsedate, seated TNE as the method of choice for PEG insertion on high risk MND patients.

\section{PTH-10 SAFETY OF ARTIFICIAL ENTERAL FEEDING IN PATIENTS WITH ACUTE-ON-CHRONIC LIVER FAILURE AND PRESENCE OF VARICES}

1,2Maciej Adler*, 'Francesca Moroni. ${ }^{1}$ NHS Grampian, Aberdeen, UK; ${ }^{2}$ University of Aberdeen, Aberdeen, UK

\subsection{6/gutjnl-2021-BSG.289}

Introduction Enteral nutrition through tube feeding forms part of the established treatment for patients with acute on chronic liver failure (ACLF) who are unable to meet their nutritional demands orally. There are concerns among gastroenterologists that nasogastric tube insertion may provoke upper gastrointestinal bleeding in this patient group, and literature in this field is lacking.

Methods We retrospectively identified 69 patients with ACLF admitted to our unit between December 2017 and February 2020 who underwent nasogastric feeding (NG) by comparing dietetic and electronic records. Epidemiology data and complications post NG insertion were collected. Multivariate analysis were calculated and a two-tailed $\mathrm{p}$ value of $\leq 0.05$ was considered significant.

Results Patients were predominantly male $(n=38,54 \%)$, with alcohol related liver cirrhosis $(n=54,78.3 \%)$. Varices were known at time of admission in 28 patients. Four patients $(5.8 \%)$ were considered to have had gastrointestinal bleeding post NG insertion, defined as new melaena $(n=1)$, haematemesis $(n=2)$, or a fall in haemoglobin accompanied by a urea rise $(n=1)$ within 72 hours. There were no differences in rate of bleeding between patients with pre-existing varices and patients without varices $(\mathrm{p}=0.84)$. In all cases bleeding was

\begin{tabular}{|c|c|c|c|}
\hline & UGIB within $72 \mathrm{~h}$ & No UGIB within & \\
\hline & & $72 \mathrm{~h}$ & \\
\hline$n$ & $\mathrm{~N}=4$ & $\mathrm{~N}=65$ & \\
\hline Age (years) & $53.25 \pm 14.6$ & $58.2 \pm 11.6$ & 0.42 \\
\hline Male, n (\%) & $3(75)$ & $1(25)$ & 0.41 \\
\hline \multicolumn{4}{|l|}{ Etiology, n (\%) } \\
\hline Alcoholic & $2(50)$ & $52(80)$ & 0.55 \\
\hline Non-Alcoholic & $2(50)$ & $13(20)$ & \\
\hline Alcohol & $43.7 \pm 71.8$ & $69.2 \pm 89.3$ & 0.62 \\
\hline Consumption & 150) & 300) & \\
\hline BMI $\left(\mathrm{kg} / \mathrm{m}^{2}\right)$ & $\begin{array}{l}22.6 \pm 4.4(18- \\
28)\end{array}$ & $24.1 \pm 6.1(14-43)$ & 0.69 \\
\hline INR & $\begin{array}{l}2.5 \pm 0.5(1.8- \\
2.8)\end{array}$ & $2.0 \pm 1.0(1.0-8.2)$ & 0.04 \\
\hline PLT $\left(x 10^{9} / \mathrm{L}\right)$ & $\begin{array}{l}113 \pm 62(59- \\
189)\end{array}$ & $156 \pm 95(33-450)$ & 0.43 \\
\hline Varices (\%) & $2(50)$ & $26(40)$ & 0.84 \\
\hline
\end{tabular}

managed conservatively without endoscopy, and it had no effect on outcomes (transfusion and mortality). Only elevated INR $(\mathrm{p}=0.04)$ was associated with bleeding, with an INR $<2$ showing a trend to significance for decreased relative risk of bleeding (RR 0.38, 95\% CI 0.20-0.76, p=0.09).

Conclusions NG tube insertion in patients with ACLF is safe but carries a small risk of gastrointestinal bleeding, associated with progressively deranged clotting parameters. This should be factored into clinical decision making.

Abbreviations UGIB, upper gastrointestinal bleed; NGT, nasogastric tube; BMI, body mass index; INR, international normalized ratio; PLT, platelet count; L, litre

\section{PTH-11 DIETETIC PROVISION FOR ADULTS WITH COELIAC DISEASE IN THE UK}

Yvonne Jeanes*, Sharon Kallos, Sidra Nasim. University Of Roehampton, London, UK

\subsection{6/gutjnl-2021-BSG.290}

Introduction Coeliac disease (CD) is estimated to affect $1 \%$ of the global population, it is associated with chronic inflammation of the small intestine and malabsorption of nutrients. Dietitians have a key role within the management of CD helping patients to exclude all gluten from their diet. The provision of dietetic service is varied and inequalities of access may be present. The study aimed to provide comprehensive description of the dietetic service provision to adults with $\mathrm{CD}$ across the UK.

Methods An online and paper survey was promoted to UK dietitians during 2018/19, before the coronavirus pandemic. Eighty-eight department responses were received. Ethical approval was granted (Reference: LSC 19/258).

Results The majority of departments (60\%) offered individual appointments for newly diagnosed adults with CD while 33\% departments offered group sessions. The predominant reasons for group sessions was peer support and reduce wait time for dietetic contact. Only 5\% of departments offered pre-recorded online content, whilst telephone and online video consultations were not available. Three quarters of dietetic departments

\section{Abstract PTH-11 Table 1}

\begin{tabular}{lllll}
\hline & $\begin{array}{l}\text { Individual } \\
\text { (in } \\
\text { person) }\end{array}$ & $\begin{array}{l}\text { Individual } \\
\text { (telephone) }\end{array}$ & $\begin{array}{l}\text { Group } \\
\text { session }\end{array}$ & $\begin{array}{l}\text { Other } \\
\text { formats* }\end{array}$ \\
& & & \\
\hline Type of review appointment offered by & $62 \%$ & $12 \% \mathrm{n}=10$ & $9 \% \mathrm{n}=7$ & $17 \%$ \\
dietetic departments & $\mathrm{n}=51$ & & & $\mathrm{n}=14$ \\
Reason for mode of delivery & & & & \\
To meet national guidelines & $61 \%$ & $40 \%$ & $57 \%$ & $50 \%$ \\
$\begin{array}{l}\text { Patient preference } \\
\text { To offer peer support }\end{array}$ & $31 \%$ & $60 \%$ & $43 \%$ & $36 \%$ \\
Reduce wait time & 0 & 0 & $100 \%$ & 0 \\
Insufficient dietetic time & $1 \%$ & $30 \%$ & $57 \%$ & $43 \%$ \\
$\begin{array}{l}\text { Do they include the following as per national guidelines } \\
\text { Collect height and weight values }\end{array}$ & $88 \%$ & $80 \%$ & $29 \%$ & $65 \%$ \\
Review symptoms & $94 \%$ & $100 \%$ & $57 \%$ & $86 \%$ \\
Review coeliac serology & $82 \%$ & $70 \%$ & $43 \%$ & $79 \%$ \\
Assess dietary adherence & $90 \%$ & $100 \%$ & $43 \%$ & $71 \%$ \\
Discuss long term complications & $73 \%$ & $70 \%$ & $57 \%$ & $29 \%$ \\
Review related co-morbidities & $59 \%$ & $70 \%$ & $0 \%$ & $21 \%$ \\
\hline
\end{tabular}


offered regular reviews for adults with $\mathrm{CD}$, detailed in the table.

Conclusions Meeting national guidance is a key driver for provision and content of reviews for adults with CD. This study provides a baseline for comparison to how the services have changed during the pandemic and beyond. There is urgent need to evaluate the acceptability of different formats and include the voice of people with CD in the design of services.

\section{PTH-12 CATHETER-RELATED INFECTION RATES IN PATIENTS ON CUSTOMIZED HOME PARENTERAL NUTRITION COMPARED TO MULTI-CHAMBER BAGS}

\footnotetext{
1,2Benjamin Crooks*, 'Simon Harrison, ${ }^{1}$ Graham Millward, ${ }^{1}$ Kirsty Hall, ${ }^{1}$ Michael Taylor, ${ }^{1}$ Kirstine Farrer, ${ }^{1}$ Arun Abraham, ${ }^{1}$ Antje Teubner, ${ }^{1,2}$ Simon Lal. ${ }^{1}$ Intestinal Failure Unit, Salford Royal NHS Foundation Trust, Salford, UK; ${ }^{2}$ The University of Manchester, Manchester, UK
}

\subsection{6/gutjnl-2021-BSG.291}

Introduction The risk of blood stream infections may be increased in hospitalized patients receiving ready-made multichamber parenteral nutrition bags (MCB) compared to customized parenteral nutrition (PN); however, as highlighted in recent international guidelines, there are no comparable data relating to home $\mathrm{PN}$ (HPN).

Methods Data from a prospectively maintained database were analysed to compare incidence rates of catheter-related blood stream infections (CRBSI) between patients receiving customized HPN compared to MCB HPN at a national UK referral centre between May 2018 and August 2020. Two patient cohorts were included:

1. Patients newly commenced on HPN (customized and MCB) for a 14 month period from July 2019.

2. Patients who were switched from customized to $\mathrm{MCB}$ HPN in July 2019.

Results Sixty patients with chronic intestinal failure were commenced on MCB and 45 on customized HPN for a total of 5914 and 7641 catheter days respectively. No difference in CRBSI incidence was found $(0.51 / 1000$ catheter days for MCB, 0.39/1000 catheter days for customized HPN; incidence rate ratio $1.29,95 \%$ CI $0.26-6.37$ )

Eighteen patients were switched from customized HPN to MCB HPN. The study period covered 7401 catheter days on customized HPN and 4834 days on MCB. No significant change was noted in the CRBSI rates following this switch $(0.27 / 1000$ catheter days on customized HPN versus 0.21 / 1000 catheter days on $\mathrm{MCB}$; incidence rate ratio $1.31,95 \%$ CI 0.12-14.3).

Conclusions The use of MCB for HPN patients is not associated with an increased risk of CRBSI. This study will inform international guidelines and provide reassurance for the continued, safe use of MCB HPN.

\section{PTH-13 ONGOING PH TESTING OF NASOGASTRIC TUBES: A REVIEW OF HOSPITAL INCIDENT REPORTS IN ADULTS}

\footnotetext{
${ }^{1}$ Kate Glen*, ${ }^{1}$ Merrilyn Banks, ${ }^{2}$ Christine Elizabeth Weekes, ${ }^{1}$ Mary Hannan-Jones. ${ }^{1}$ Queensland University of Technology, Brisbane, Australia; ' ${ }^{2}$ Guy's and St Thomas' Hospitals NHS Foundation Trust, London, UK
}

Introduction It is unknown if $\mathrm{pH}$ testing a nasogastric tube (NGT) before every use reduces the risk of adverse outcomes as it is based on expert opinion ${ }^{(1,2)}$. Adverse outcomes such as never events are rare, 95 in 4.5 year period across England, with 790,000 NGTs supplied annually ${ }^{(1)}$ making this difficult to observe such incidents in cohort studies. This review of hospital NGT incident data aims to identify incidents related to ongoing $\mathrm{pH}$ testing, at a central London hospital which orders approximately 5,000 NGTs annually.

Methods The hospital's Risk Systems Manager searched all incident data from 1-Jan-2014 to 31-Dec-2019 for [Nasogastric OR NG] AND tube. Anonymised short incident descriptions were shared with the authors who compared the incidents to inclusion/exclusion criteria (see figure 1). More detailed incident records were requested for included incidents and compared against the criteria. Incidents were analysed using descriptive statistics. This review considered a service evaluation, so no ethical approval required.

Results See figure 1 for results. The initial search returned 352 incidents. Further description obtained for 22 incidents,

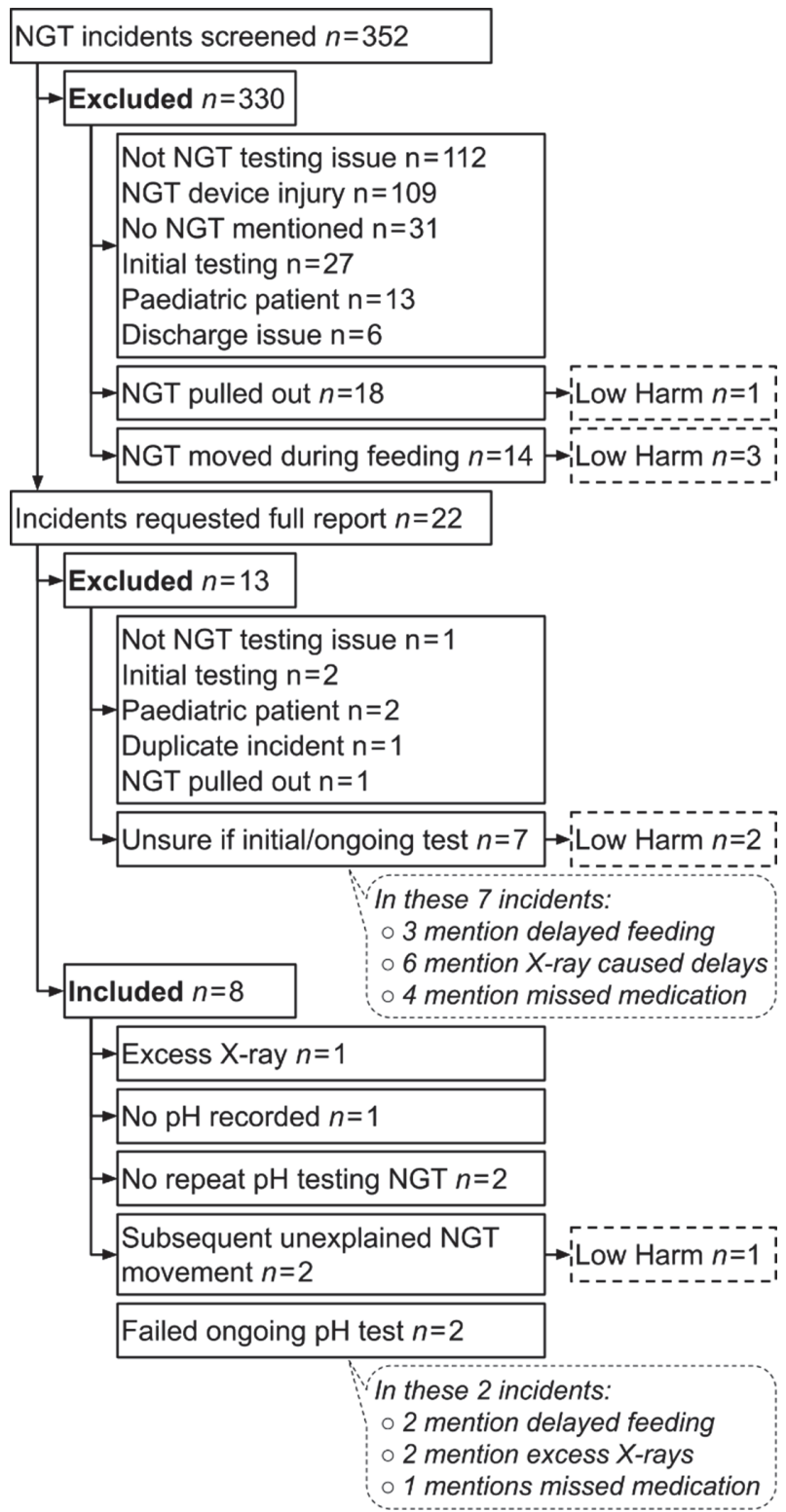

Abstract PTH-13 Figure 1 Classification tree of incidents 